Saudi Journal of Medicine

Abbreviated Key Title: Saudi J Med ISSN 2518-3389 (Print) |ISSN 2518-3397 (Online) Scholars Middle East Publishers, Dubai, United Arab Emirates Journal homepage: http://scholarsmepub.com/sjm/

Case Report

\title{
Nasopharyngeal Rhinosporidiosis - A Case Report
}

Dr. Dipin Koodali ${ }^{1}$, Dr. Bhagyashree Sagane ${ }^{1}$, Dr. Yessukrishna Shetty ${ }^{2 *}$, Dr. Cassandra Carvalho ${ }^{3}$, Dr. Haritosh K Velankar ${ }^{4}$

${ }^{1}$ Junior Resident, Department of E.N.T and Head and Neck Surgery, Dr. D. Y. Patil Hospital, Navi Mumbai, India

${ }^{2}$ Assistant Professor, Department of E.N.T and Head and Neck Surgery, Dr. D. Y. Patil Hospital, Navi Mumbai, India

${ }^{3}$ Senior Registrar, Department of E.N.T and Head and Neck Surgery, Dr. D. Y. Patil Hospital, Navi Mumbai, India

${ }^{4}$ Professor and Head of the Unit and ex-HOD, Department of E.N.T and Head and Neck Surgery, Dr. D. Y. Patil Hospital, Navi Mumbai, India

DOI: $10.36348 /$ sjm.2019.v04i11.007

| Received: 20.11.2019 | Accepted: 27.11.2019| Published: 30.11.2019

*Corresponding author: Dr. Yessukrishna Shetty

\section{Abstract}

Rhinosporidiosis is a chronic granulomatous mucocutaneous infecion caused by Rhinosporidium seeberi. The infection is non-contagious and as the name suggests, it is primarily a disease of the nose. Here, we report a rare case of rhinosporidiosis affecting the nasopharynx in a 35 year old male patient.

Keywords: Endospores, nasal mass, nasopharyngeal mass, Rhinosporidium seeberi, Rhinosporidiosis.

Copyright @ 2019: This is an open-access article distributed under the terms of the Creative Commons Attribution license which permits unrestricted use, distribution, and reproduction in any medium for non-commercial use (NonCommercial, or CC-BY-NC) provided the original author and source are credited.

\section{INTRODUCTION}

Rhinosporidiosis is reported most commonly from Southern India, Srilanka and Bangladesh [1].

Disease is seen to involve animals such as bulls, cows and dogs where humans and animals share the same infected ponds. Clinically it presents most commonly as a polypoidal soft tissue mass of nose but it can present at other mucous membranes and mucocutaneous surfaces also.

\section{CASE REPORT}

A 35 year old male paddy cultivator from a village in Maharashtra came to our out patient department with complaints of foreign body sensation in throat since one month. Patient did not give any history of respiratory distress, pain, oral bleed, hemoptysis or change in voice. On detailed history, it was discovered that the patient is a known case of hypertension since 6 years and was on medication for the same. It also came to our notice that the patient is suffering from recently diagnosed Stage IV chronic kidney disease.

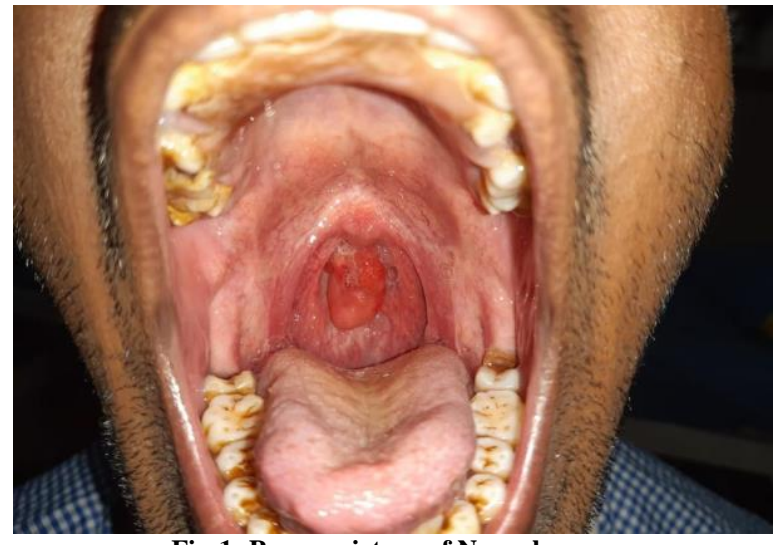

Fig-1: Pre-op picture of Nasopharynx

Anterior rhinoscopy revealed deviated nasal septum to right with bilateral inferior turbinate hypertrophy. Throat examination showed a solitary, $4 \mathrm{~cm} \times 1.5 \mathrm{~cm} \times 1 \mathrm{~cm}$, non-tender, erythematous polypoidal mass which is soft in consistancy, that was hanging into the oropharynx. The mass was nonpulsating or expansile and did not bleed on touch. No clinically significant lymph nodes were noticed.

Routine blood investigations were sent for the patient and the serum creatinine level was reported to be $6.4 \mathrm{mg} / \mathrm{dL}$. Contrast imaging was not done as the renal functions were deranged. HRCT Paranasal Sinuses showed multiple small pyramidal soft tissue mass lesions arising from posterior pharyngeal wall. 
The patient was transferred to the department of nephrology for the management of chronic kidney disease and where he underwent 3 sessions of hemodialyis. Patient was planned for nasopharyngeal mass excision post final fitness from nephrology and anaesthesia departments.

A diagnostic nasal endoscopy was performed prior to the surgery to rule out the presence of any nasal masses or the extension of the nasopharyneal growth into the nose.

Nasopharyngeal mass excision was done and the base was cauterized, and the tissue excised was sent for histopathological examination.

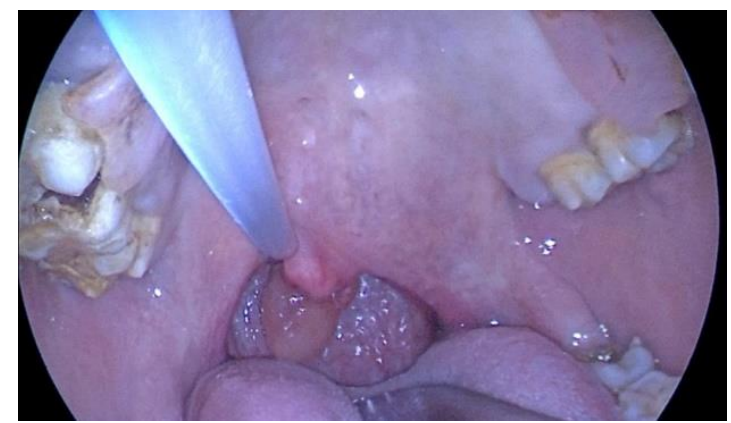

Fig-2: Intra-operative picture of the nasopharyngeal mass

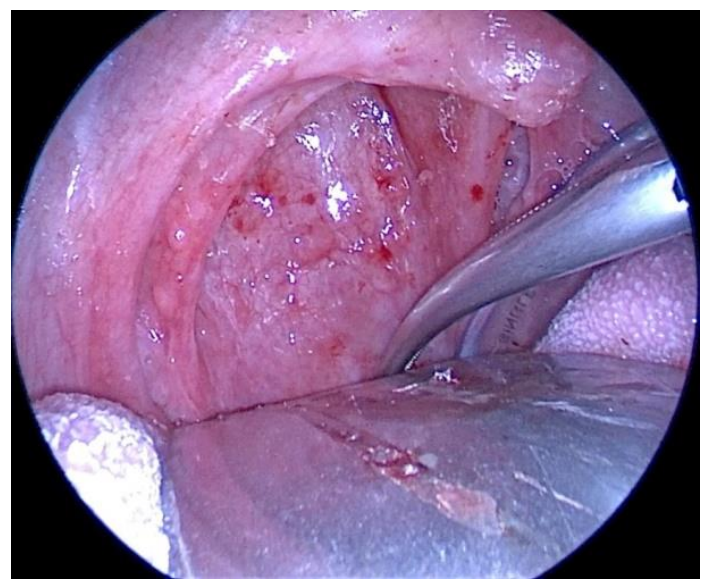

Fig-3: Nasopharynx after excision of the nasopharyngeal mass

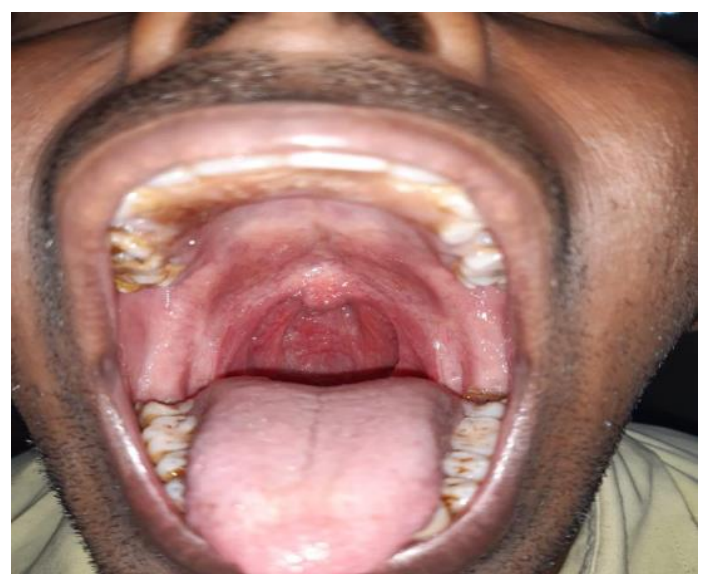

Fig-4: Picture on follow up two weeks after the surgical excision of the nasopharyngeal mass
Gross examination of the surgically excised tissue showed polypoidal mass measuring $3 \mathrm{~cm} \times 1.5 \mathrm{~cm}$ $\mathrm{x} 1 \mathrm{~cm}$ size with glistening external surface and whitish cut surface.

Microscopic examination of the specimen showed polypoidal tissue bits lined by non-keratinizing stratified squamous epithelium. Submucosa showed thick walled sporangium filled with endospores along with oedema and plenty of dilated and congested blood vessels. Stroma shows mixed inflammatory cell infiltrate composed of lymphocytes, plasma cells and foreign body giant cells. These features were suggestive of rhinosporidiosis.

After confirming the histopathology report, he was started on a course of Dapsone and the patient was adviced to follow up every week for 3 months.

\section{DISCUSSION}

Rhinosporidiosis is a chronic granulomatous lesion of the mucocutaneous zone and primarily the mucosa of nose, conjunctiva and urethra. First known case was identified in 1892 and the first detailed account of Rhinosporidiosis was given by Guillermo Seeber in 1900 [1].

The term rhinosporidiosis originated from the typical lesions caused by the organism. Rhinosporidium usually infects the mucosa of nose and produce a polypoidal mass-like lesion with granular surface speckled with whitish spores.

The causative agent of rhinosporidiosis, Rhinosporidium seeberi, has long been considered to be a fungus, but presently it is reclassified in a new DRIP clad (Dermocystidium, Rosette agent, Ichthyophonus and Psorospermum) which include fish and amphibian pathogen $[2,3]$.

The age group most commonly affected is the 21-50 years age group, with the 31-40 years age group having the highest predilection for infection. Male to female ratio observed is $4: 1$ [4].

Most of the cases are reported from rural areas of India, Srilanka and Pakistan. Cases have also been reported from Kenya, Tanzania, Rwanda, Egypt, Argentina and Brazil. In India, the disease is more prevalent in Southern states of Tamil Nadu, Kerala, Andhra Pradesh and Puducherry.

Rhinosporidiosis predominantly affects nose. Other areas of involvement include conjunctiva, nasopharynx, lacrimal sac, lips, palate, uvula, maxillary antrum, epiglottis, larynx, trachea, bronchi, ear, scalp, penis, vulva and vagina. In $53 \%-58 \%$ of the cases, lesions are seen on nose and $12 \%-17 \%$ on nasopharynx while ocular conjunctiva and other sites are affected in $30 \%$ of cases. 
Most common ways of presentation include blood tinged nasal discharge, nasal stuffiness, foreign body sensation, post nasal discharge with cough and epiphora and phtophobia in conjunctival involvement.

Reservoir of infection is believed to be soil and water since a high incidence of infection is seen in paddy cultivators, sand workers and people bathing in stagnant muddy water. Exact mechanism of transmission is not well understood yet, but the entry is believed to be through traumatized epithelium. Endospore from infected water penetrate the nasal mucosa, mature into sporangia within submucosa and on maturation, burst and release sporangia into surrounding tissues [5].

Clinically Rhinosporidiosis presents as polypoidal, soft tissue mass in nose, throat, eye, oropharynx, larynx, trachea, bronchi and genitourinary tract.

But since the disease has a slow progession, most of the cases remain undiagnosed for a long period of time until the symptoms appear, posing a real challenge to clinicians. Thus the incidence of the disease is surprisingly low even in endemic areas [6].

Nasopharyngeal angiofibroma, a vascular tumor-like lesion, occuring in the nasopharynx can mimic rhinosporidiosis clinically and radiologically. However it is more destructive occurs mostly in younger population.

Another clinically confusing entity that can present in the nasopharynx is nasopharyngeal carcinoma, but it presents in more rapid and destructive course, associated with pain, cervical lymph node involvement and with possibility of metastasis at the time of presentation.

Micotic granulations, though rare, can appear in nasopharynx in immunocompromised individuals, but histopathological examination helps to differentiate it.

Osteolytic bone lesion is another pathognomic feature of Rhinosporidiosis [7].

Complete excision of the mass with diathermy knife and cauterization of the base is the mainstay of treatment. Recurrance may occur after surgical excison and to reduce the risk of recurrance, wide surgical margin is required. The only drug that appeared to have shown some clinical promise in treating Rhinosporidiosis is Dapsone, which appears to arrest the maturation of the sporangia and to promote fibrosis in the stroma, when used as an adjunct to surgery [8, 9]. Dapsone inhibits synthesis of dihydrofolic acid, via competition with para-aminobenzoate for the active site of dihydropteroate synthase. Therefore folic acid suppliment has to be given as interval therapy when dapsone is being given [10].

\section{CONCLUSION}

Rhinosporidiosis should be considered a differential diagnosis by pathologists and clinicians while dealing with nasal and nasopharyngeal masses especially in endemic areas while keeping in mind that angiofibromas, nasopharyngeal carcinomas, polyps, papillomas and minor salivary glands can also present as a sessile or pedunculated mass like this. Imagimg studies and histopathological examination plays a key role in ruling out other causes of nasopharyngeal masses.

Post-operative follow-up at regular intrervals must be made on a long term basis for the risk of recurrence.

Since this disease almost exclusively occurs in individuals from low socioeconomic class, who often uses stagnant water from infected ponds, a large scale public health education in endemic areas can reduce the incidence of this exasperating condition.

\section{ACKNOWLEDGEMENTS}

We would like to acknowledge the Head of the Department of E.N.T, Dr. Yogesh G Dabholkar, the Dean of the Dr. D Y Patil Medical College, Dr. Surekha Patil and the Superintendent of Dr. D.Y Patil Medical College, Dr. Rahul Pedawad for their help and support.

\section{REFERENCES}

1. Babu, S., Anuradha, A., Chandra, S., \& Kashyap, B. (2012). Rhinosporidiosis: A case report with review of literature. Annals of Tropical Medicine and Public Health, 5(2), 127.

2. Satyanarayana, C. (1960). Rhinosporidiosis: with a record of 255 cases. Acta otolaryngologica, 51(3-4), 348-366.

3. Herr, R. A., Ajello, L., Taylor, J. W., Arseculeratne, S. N., \& Mendoza, L. (1999). Phylogenetic analysis of Rhinosporidium seeberi's 18S small-subunit ribosomal DNA groups this pathogen among members of the protoctistan Mesomycetozoa clade. Journal of Clinical Microbiology, 37(9), 2750-2754.

4. Von Haacke, N. P., Mugliston, T. A. (1982). Rhinosporidiosis. The Journal of Laryngology \& Otology. 96(8):743-50.

5. Putthia, H., Manjunatha, B. S., Astekar, M., \& Taufiq, S. (2018). Palatal rhinosporidiosis: an unusual case report and review of the literature. Journal of the Korean Association of Oral and Maxillofacial Surgeons, 44(6), 293-297.

6. Das, S., Kashyap, B., Barua, M., Gupta, N., Saha, R., Vaid, L., \& Banka, A. (2011). Nasal rhinosporidiosis in humans: new interpretations and a review of the literature of this enigmatic disease. Medical mycology, 49(3), 311-315. 
7. Nambiar, S. S., Radhakrishnan, S., \& Vijayan, A. (2017). Rhinosporidiosis: report of an extra-ductal facial lesion. IDCases, 7, 40-43.

8. Arseculeratne, S. N. (2002). Recent advances in rhinosporidiosis and Rhinosporidium seeberi. Indian journal of medical microbiology, 20(3), 119.
9. Venkateswaran, S., Date, A., Job, A., \& Mathan, M. (1997). Light and electron microscopic findings in rhinosporidiosis after dapsone therapy. Tropical Medicine \& International Health, 2(12), 1128-1132.

10. Kurien, G., \& Pellegrini, M. V. (2018). Dapsone. InStatPearls. StatPearls Publishing. 